\title{
2.|||||||||||||||||||||||||||||||||||||||||||||||||||||||||||||||||||||.
}

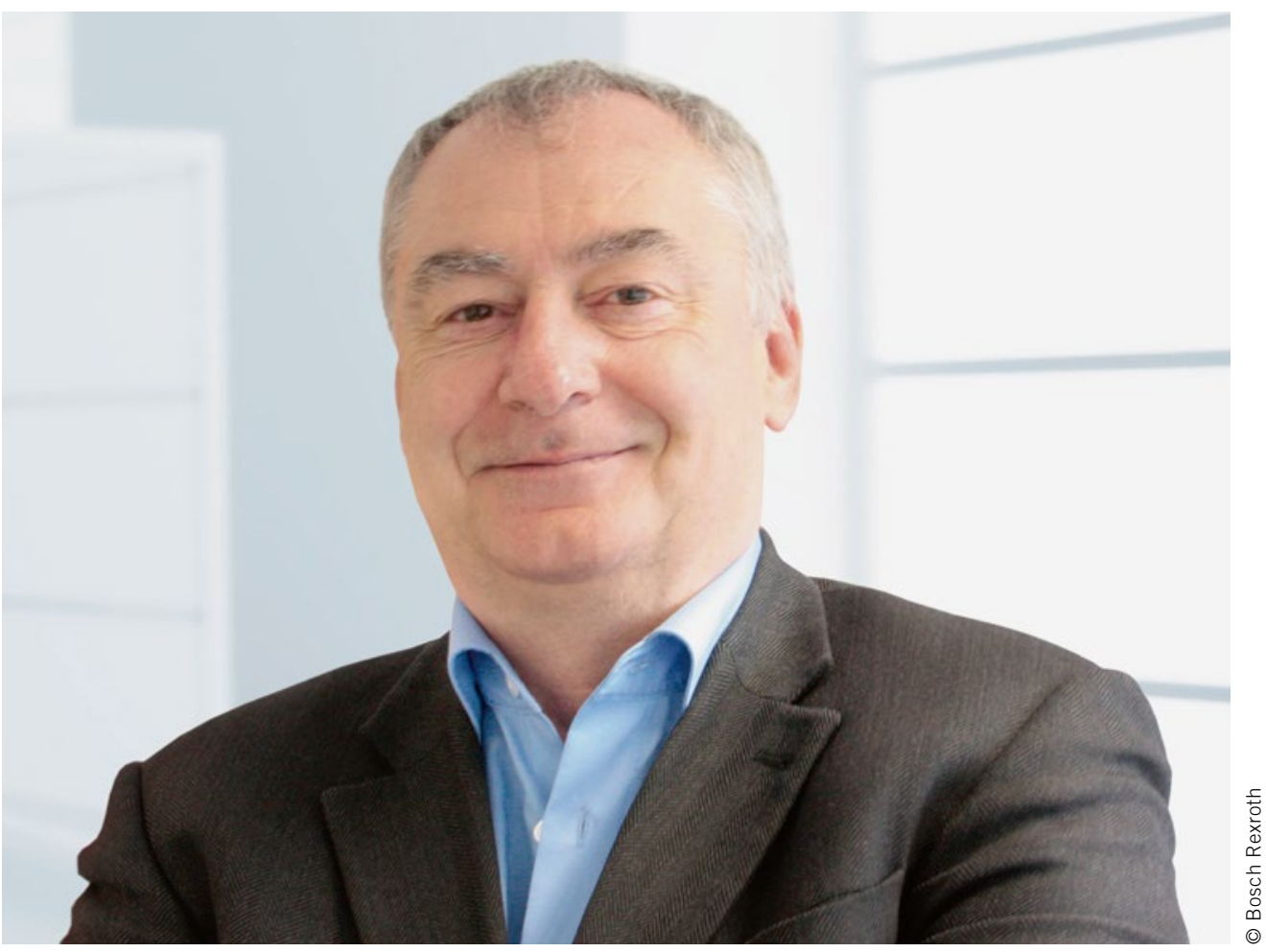

Karlheinz Vogl

Leiter Vertrieb und Branchenmanagement Baumaschinen der Bosch Rexroth AG in Lohr

\section{Baumaschinen - intelligent bei der Arbeit, sparsam im Verbrauch}

In vielen Segmenten der Baumaschinenindustrie wird zumindest mittelfristig eine Erholung der Märkte erwartet. Die Nachfragesituation in China beispielsweise zeigt bereits positive Tendenzen. Auch in den restlichen asiatischen Regionen geht man von einer positiven Entwicklung aus, und der Markt in Europa ist aktuell weitestgehend stabil. Neben der konjunkturellen Entwicklung beschäftigt Hersteller wie Anwender gleichermaßen die weltweit gestiegene Komplexität gesetzlicher Vorgaben. Emissionsvorgaben wie die Stufe IV in Europa oder die Tier 4 final in den USA bilden den Rahmen für künftige Entwicklungen. Entscheidend dabei ist, dass die gewohnte Leistung und die Agilität der Hydraulik weiter gesteigert werden.

Arbeits- und Fahrhydraulik liefern bereits heute erhebliche Beiträge, den Dieselverbrauch und damit die Abgasemissionen von Baumaschinen stark zu verringern. Doch allein mit energieeffizienten Komponenten lässt sich diese Herausforderung nicht stemmen. Viel wichtiger ist deren Zusammenspiel: Dieselmotor, hydrostatischer Fahrantrieb und Arbeitshydraulik sollten hierfür im optimalen Betriebspunkt betrieben werden. Häufig müssen Systeme sogar grundlegend neu entwickelt werden, um die künftigen Anforderungen erfüllen zu können.

An Bedeutung gewinnt in diesem Zusammenhang auch die Abgasnachbehandlung, die zunehmend Platz in der Baumaschine fordert. In Folge wird Bauraum ein knappes Gut. Fein abgestufte Nenngrößen, aber auch intelligente Konstruktionen, beispielsweise in Antriebseinheiten integrierte Bremsen, helfen, den vorhandenen Bauraum optimal zu nutzen.

Von der energieeffizienten Baumaschine der Zukunft erwarten Anwender ein ebenso flexibles wie komfortables Arbeitsgerät - und das maßgeschneidert auf die Gegebenheiten und Kundenanforderungen vor Ort. Die Anforderungen an Steuerbarkeit und Vernetzbarkeit sind in diesem Zusammenhang gestiegen. Dies kann nur durch eine zunehmende Elektronifizierung der Hydraulik realisiert werden: Sensoren, etwa für Position, Druck oder Temperatur, werden in die Hydraulik integriert und bilden die Basis für die Erfassung und Weiterleitung von Messdaten. Sie liefern die Voraussetzung für die funktionale Diagnose elektronifizierter Antriebslösungen und ermöglichen eine zustandsorientierte Wartung. Die Verfügbarkeit der Baumaschine kann so weiter gesteigert werden. 